\title{
Editorial
}

\section{Os afetos na pandemia da Covid-19 e a política da imobilização psíquica}

Emotions during the Covid-19 pandemic and the politics of psychological immobilization

\author{
Maria Livia Tourinho Moretto*1 \\ Nelson da Silva Jr. ${ }^{* 2}$
}

Em seu Editorial da Revista Latinoamericana de Psicopatologia Fundamental, há menos de um ano, em setembro de 2020, Ana Maria Oda e Sonia Leite, registravam: "o número de óbitos causados pela pandemia de Covid-19 (doença pelo novo coronavírus) já ultrapassa 142 mil pessoas no Brasil, e o número de casos de infecção chega a quase 4,8 milhões. No mundo, são mais de 1 milhão de mortes e 33 milhões de casos" (Oda \& Leite, 2020). Entre seus efeitos de horror e de entorpecimento, as Editoras já apontavam o caráter inominável subjacente às cifras daquele momento.

Hoje, em junho de 2021, as cifras brasileiras ultrapassaram 470.000 em número de mortos pela pandemia e cerca de 16.841.954 de casos infectados. Desde então, reafirmou-se o caráter evitável de pelo menos um quinto dessas mortes: pelo menos 94.000 teriam sido evitadas caso o governo federal tivesse

*1,2 Universidade de São Paulo - USP (São Paulo, SP, Brasil) . 
agido com seriedade e responsabilidade diante da realidade da pandemia e da possibilidade de atenuar seus efeitos, como por exemplo, adquirindo as vacinas quando foram oferecidas e aproveitado a rede do SUS já em funcionamento para sua distribuição planificada. Alguns aspectos desse genocídio receberam seus nomes, e ao lado do horror e do entorpecimento, outros afetos tomaram a cena, como a indignação com o caráter intencional dessas mortes, como tem se tornado claro na CPI da Covid. Mas, para além da indignação, outro afeto tem insistido, a saber, o espanto com a servidão voluntária de extensas camadas da população brasileira diante de um chefe de estado populista, que fomenta a violência, a precedência da economia sobre as vidas humanas e cuja atuação antidemocrática tem visado desautorizar as instituições públicas de modo sistemático. Hoje, ao lado do risco da pandemia, novas sombras ameaçam a vida pública brasileira como, por exemplo, a violência desenfreada de um Estado de Direito que se articula às milícias e, assim, favorece o retorno ao regime do Estado da força.

Alguns índices mostram o sofrimento psíquico decorrente desse estado de coisas. O impacto da pandemia na saúde mental e na qualidade de vida dos brasileiros pode ser notado pelo aumento de casos de suicídio, depressão, ansiedade e violência doméstica. De acordo com Rocha et al. (2021) os comprometimentos psicológicos têm sido expressos também por instabilidades de humor, níveis elevados de ansiedade, situação de estresse, frustração, solidão, raiva e alteração de padrão de sono. Fatores associados à duração prolongada da medida de confinamento, às possibilidades de contágio, às instabilidades econômicas, ao desconhecimento e às incertezas que permeiam a doença, são determinantes para o grau de sofrimento psíquico.

A Psicopatologia Fundamental não poderia deixar de refletir sobre essa situação catastrófica a partir de seu próprio campo conceitual. Freud (1914/1982b) define o sofrimento como uma experiência ligada ao narcisismo, recorre ao humor (Freud, 1927/1980) como uma possibilidade de defesa frente ao sofrimento, e afirma, no texto "Mal-estar na civilização", que ele é derivado de três fontes: do próprio corpo (por meio do processo de adoecimento), do mundo exterior (que pode voltar-se contra nós com forças de destruição esmagadoras e impiedosas) e da relação com os outros homens (supondo que esta última seja a mais penosa entre as três fonte mencionadas) (Freud, 1930/1982d).

A pandemia da Covid-19 potencializa essas três fontes de sofrimento em um único acontecimento: em primeiro lugar, atinge o corpo de cada um de modo imprevisível, alguns permanecendo assintomáticos, e outros tendo um 
desfecho fatal a partir da infecção; em segundo lugar, representa uma ameaça invisível que parte do exterior, ameaça que atinge o planeta por inteiro e exige uma postura preventiva diante dela, alterando nossas formas de vida de modo inédito; e, finalmente, ceifa vidas que nos são caras, privando os enlutados até mesmo dos obséquios, cuja dimensão pública cumpre o papel de nos auxiliar a desinvestirmos dos que foram e novamente abraçarmos a vida.

Caso avancemos nossa reflexão em direção às estruturas psíquicas afetadas pelo impacto dessas três fontes, Freud nos convida a trabalhar a partir da premissa de que há uma dimensão sociopolítica do sofrimento (Debieux-Rosa, 2016). A primeira constatação é que a sobreposição de fatores traz sérios obstáculos à tradução dessas experiências em palavras, o que tende a impelir os sujeitos a vivenciá-las na lógica do trauma (Green, 2000).

De fato, o aumento dos índices epidemiológicos ligados ao sofrimento psíquico confirma uma premissa da psicanálise a respeito da participação da dimensão social na estrutura psíquica. Para Freud, o aparelho psíquico é, desde o início, não apenas radicalmente aberto à dimensão social, como também estruturado por essa dimensão. Nessa premissa estão presentes duas teses sobre o sofrimento psíquico. Primeiramente a tese que as patologias são dependentes da organização social em que surgem. Trata-se de um tema explicitamente abordado por Freud, pelo menos desde 1908, em seu texto "A moral sexual civilizada e a neurose moderna" (Freud, 1908/1982a) onde apontou o caráter patogênico de uma excessiva exigência de sublimação da sexualidade por parte da cultura vienense da época. Nesse primeiro tempo, a patogênese da sublimação está na origem dos sintomas neuróticos, caso ela ocorra em excesso. A premissa freudiana de que o sujeito se estruture a partir da sociedade em que vive, retoma uma tradição de crítica social inaugurada com Rousseau; é apresentada de forma independente por Marx e tem sido central no Instituto de Pesquisa Social desde Adorno e Horkheimer. Premissa que afirma a historicidade das formas de pensar e sentir, e, portanto, o caráter social de todo sofrimento individual.

Num segundo tempo de sua obra, após a introdução da pulsão de morte na economia psíquica, a sublimação inerente à formação do Superego terá o poder de desfusionar a pulsão de morte das pulsões de vida, para, em seguida, refusioná-las sob a forma do masoquismo moral (Freud, 1924/1982c). Nesse caso, o sofrimento assume um estatuto de inevitabilidade, donde a expressão Patologias das comunidades culturalizadas, presente em "Mal-estar na civilização" (1930/1982d). Esta é a resposta de Freud ao grande enigma da filosofia política descrito por La Boétie (1553/1976) e conhecido como a 
Servidão Voluntária: "Por que milhares de pessoas voluntariamente sacrificam sua liberdade a um tirano sem serem coagidas a isso pela força física?" Isto é, como entender a servidão voluntária?

A hipótese freudiana é consistente para sua época. Ela permite uma interpretação forte sobre a sedução exercida pelas ideologias totalitaristas e seus líderes, coisa que o século XX testemunhou abundantemente. De fato, o masoquismo moral sempre esteve solidamente apoiado em dois polos: a economia psíquica organizada pelo complexo de Édipo e a cultura patriarcal ocidental. As religiões e as instituições sociais correlatas, como a família, a educação e a justiça, funcionam como discursos que valorizam o sacrifício. Nesse contexto, o sacrifício aos ideais gera um aumento exponencial da satisfação masoquista do Ego, como também do rigor das exigências do Superego, o que foi exemplarmente descrito por Freud em "Moisés e a religião monoteísta" (1937/1982e).

Em ambos os casos, os impactos de tais fatores patogênicos endógenos dependem da relação dos sujeitos com a verdade dos próprios afetos: sejam eles desejos eróticos, desejos de crueldade ou desamparo. Verdade, portanto, no sentido grego de desvelamento, resgatado por Heidegger, e interpretado em Ser e Tempo (Heidegger, 1927/1979), como um confronto com nossa intolerável finitude. A fuga incessante da própria verdade tem sido a principal abertura do psiquismo à manipulação por parte do outro, seja ele a indústria cultural, seja ele o governo. Com efeito, as patologias do social podem ser consideradas não apenas "restos" indesejáveis de uma cultura, mas produtos inerentes a elas, elas também revelam o modo que cada sociedade nomeia o tratável e o intratável de si mesma. Em tais nomeações do tratável e do intratável reside seu modo de gestão do sofrimento, tal como demonstrou Michel Foucault em sua História da loucura (Foucault, 1964/1978). A nomeação e gestão social dos afetos se revelam como instrumentos de gestão social (Cerqueira Filho, 2005; Safatle, 2016; Safatle, Silva Junior \& Dunker, 2020).

Cabe, portanto, retomar os afetos de horror, entorpecimento, indignação e espanto que a população brasileira tem sofrido a partir dessa perspectiva política de gestão dos afetos. Ao serem traduzidos exclusivamente como resultantes de disfunções orgânicas, os sofrimentos adquirem formas de nomeação que distanciam os sujeitos da experiência de uma vida em comum. Claro está que, ao excluir dele todas as causas sociais e históricas, esta resignificação do sofrimento implica necessariamente sua despolitização. Contudo, a atuação do Governo Federal deu um passo além dessa forma já tradicional de alienação política que separa os sofrimentos da situação social 


\section{EDITORIAL}

em que surgem. Com uma estratégia de desmentidos constantes, sabotagem incansável da suposição de uma realidade compartilhada através das fakenews, práticas de intimidação a jornalistas e cientistas que ousam discordar e denunciar as inconsistências, a incompetência e a má-fé no uso dos aparelhos de Estado, o que temos que reconhecer é que o entorpecimento, a paralisia e o espanto se tornaram os principais afetos de gestão instrumental do Estado brasileiro. Fomentar o caos social e a imobilização psíquica tem aparentemente sido uma estratégia temerária para atingir um sinistro objetivo de apropriação pessoal de um poder que é do povo.

É nesse momento íngreme de nossa história, onde a ciência tem sido um alvo preferencial de ataque, que assumimos a responsabilidade de dar continuidade à RLPF em sua longa e consistente trajetória editorial. Desde seu fundador e primeiro Editor, Manoel Tosta Berlinck, a RLPF tem se consagrado como uma revista que abrange não somente pesquisas relacionadas às clínicas da psicologia, da psicanálise e da psiquiatria em sentido estrito, mas também estudos sobre a subjetividade em suas articulações mais amplas com a história, a filosofia, as ciências sociais, as artes e a cultura em geral. Esse estímulo a perspectivas interdisciplinares na abordagem da psicopatologia constitui a principal singularidade da revista frente aos periódicos da chamada área "psi" (Psicologia, Psiquiatria, Psicanálise e Saúde Mental) existentes no Brasil e internacionalmente. Recebemos a RLPF em um momento privilegiado de sua história, garantido não apenas pela regularidade e alta qualidade de suas publicações, como também em vista das conquistas realizadas por suas três últimas editoras: Ana Rudge, Sonia Leite e Ana Maria Oda que deram passos decisivos em sua organização interna, no aprimoramento de seus processos de edição com a adoção da plataforma ScholarOne, na maturação de sua linha editorial, no reforço e ampliação da vocação interdisciplinar da revista, na busca de alternativas criativas para sua autonomia e equilíbrio financeiro, na implantação de critérios acadêmicos para a submissão de artigos, como a exigência de Orcid dos autores.

Diante de nós, outros desafios se impõem, para além da manutenção das conquistas realizadas até agora. Em nome da importância da pontualidade e da qualidade da informação, estabelecemos como metas a redução máxima possível dos prazos entre submissão do manuscrito, sua avaliação e decisão editorial final e a implementação de um sistema de detecção de plágio.

Estamos cientes e atentos ao fato de que o espaço editorial para a psicopatologia e para a psicanálise estreita-se cada vez mais dentre os periódicos científicos de alto impacto. A sobrevivência de uma disciplina no 
mundo editorial depende, sem dúvida, de sua visibilidade nos grandes fóruns intelectuais mundiais e de suas repercussões no âmbito acadêmico.

Firmamos, com empenho e entusiasmo, o nosso compromisso de investir na ampliação da circulação da RLPF no âmbito internacional, promovendo ações em busca de cooperação internacional, seja pelo aumento da publicação de autores estrangeiros em nossa revista, favorecendo os avanços nas trocas científicas, seja por meio de ações que aumentem o impacto de publicações derivadas das pesquisas produzidas em nosso país, acarretando maior visibilidade da ciência brasileira.

\section{Referências}

Cerqueira Filho, G. (2005). Autoritarismo afetivo: a Prússia como sentimento. São Paulo, SP: Escuta.

Debieux-Rosa, M. (2016). A clínica psicanalítica em face da dimensão sociopolítica do sofrimento. São Paulo, SP: Escuta.

Foucault, M. (1978). História da loucura. São Paulo, SP: Perspectiva. (Trabalho original publicado em 1964).

Freud, S. (1980). O humor. In Edição Standard Brasileira das Obras Psicológicas Completas de Sigmund Freud (Vol. XXI). Rio de Janeiro, RJ: Imago. (Trabalho original publicado em 1927).

Freud, S. (1982a). Die "kulturelle" Sexualmoral und die moderne Nervosität. Studienausgabe (Vol. IX). Frankfurt-am-Main: Fisher Taschenbuch Verlag. (Trabalho original publicado em 1908).

Freud, S. (1982b). Zur Einführung des Narzißmus. Studienausgabe (Vol. III). Frankfurt-am-Main: Fisher Taschenbuch Verlag. (Trabalho original publicado em 1914).

Freud, S. (1982c). Das ökonomische Problem der Masochismu. Studienausgabe (Vol. III). Frankfurt-am-Main: Fischer Taschenbuch Verlag. (Trabalho original publicado em 1924).

Freud, S. (1982d). Das Unbehagen in der Kultur. Studienausgabe (Vol. IX). Frankfurtam-Main: Fisher Taschenbuch Verlag. (Trabalho original publicado em 1930).

Freud, S. (1982e). Der Mann Moses und die monotheistische Religion, Studienausgabe (Vol.IX). Frankfurt-am-Main: Fischer Taschenbuch Verlag. (Trabalho original publicado em 1937).

Green, A. (2000). La position phobique centrale: avec un modèle de l'association libre. Revue Française de Psychanalyse, 3(64),743-771. 


\section{EDITORIAL}

Heidegger, M. (1979). Sein und Zeit. Tübingen: Max Niemeyer Verlag. (Trabalho original publicado em 1927).

La Boétie (1976). Le discours de la servitude volontaire. Paris, FR: Payot.

Oda, A. M., \& Leite, S. (2020, set.) A pandemia de COVID-19 no Brasil: em busca de sentidos em meio à tragédia. Rev. Latinoam. Psicopat. Fund., 23(3), 467-473

Rocha, D. M., Silva. J. S., Abreu, I. M., Mendes, P. M., Leite, H. D., \& Ferreira, M. C. (2021). Efeitos psicossociais do distanciamento social durante as infecções por coronavírus: revisão integrativa. Acta Paul Enferm. 34:eAPE01141. DOI: http:// dx.doi.org/10.37689/acta- ape/2021AR01141

Safatle, V. (2016). O circuito dos afetos. Belo Horizonte, MG: Autêntica.

Safatle, V., Silva Junior, N., \& Dunker, C. I. (2020). O neoliberalismo como gestão do sofrimento. Belo Horizonte, MG: Autêntica.

Citação/Citation: Moretto, M. L. T., \& Silva Junior, N. da (2021, jun.). Editorial. Os afetos na pandemia da Covid-19 e a política da imobilização psíquica. Revista Latinoamericana de Psicopatologia Fundamental, 24(2), 243-250. http://dx.doi. org/10.1590/1415-4714.2021v24n2p243.1

Editoras/Editors: Profa. Dra. Ana Maria Galdini R. Oda e Profa. Dra. Sonia Leite

Recebido/Received: 4.6.2021 / 6.4.2021 Aceito/Accepted: 7.6.2020 / 6.7.2020

Copyright: (C) 2009 Associação Universitária de Pesquisa em Psicopatologia Fundamental/ University Association for Research in Fundamental Psychopathology. Este é um artigo de livre acesso, que permite uso irrestrito, distribuição e reprodução em qualquer meio, desde que o autor e a fonte sejam citados / This is an open-access article, which permits unrestricted use, distribution, and reproduction in any medium, provided the original authors and sources are credited. 


\section{Maria Livia Tourinho Moretto}

Professora Titular do Departamento de Psicologia Clínica, Instituto de Psicologia da Universidade de São Paulo (São Paulo, SP, Br); Editora da Revista Latinoamericana de Psicopatologia Fundamental (São Paulo,SP, Br).

Avenida Professor Mello Moraes 1721 - Cidade Universitária

05508-030 São Paulo, SP, Br

liviamoretto@usp.br

https://orcid.org/0000-0002-8446-4640

Nelson da Silva JR.

Professor Titular do Departamento de Psicologia Social e do Trabalho, Instituto de Psicologia da Universidade de São Paulo (São Paulo, SP, Br); Editor da Revista Latinoamericana de Psicopatologia Fundamental (São Paulo, SP, Br).

Avenida Professor Mello Moraes 1721 - Cidade Universitária

05508-030 São Paulo, SP, Br

nelsonsj1961@gmail.com

https://orcid.org/0000-0002-2454-5019

This is an open-access article, which permits unrestricted use, distribution, the original authors and sources are credited. 